Article

\title{
Sustainable Development of Mountain Hotels through the Implementation of International Management Standards: The Romanian Case
}

\author{
Daniela Firoiu ${ }^{1}$, George H. Ionescu ${ }^{2, *}$ (D) , Roxana Bădîrcea ${ }^{3}$, Luminița Vochița ${ }^{4}$ and \\ Maria Enescu ${ }^{5}$ \\ 1 Department of Commerce, Economic Integration and Business Administration, \\ Romanian-American University, 012101 Bucharest, Romania; firoiu.daniela@profesor.rau.ro \\ 2 Department of Finance, Credit and Accounting, Romanian-American University, 012101 Bucharest, Romania \\ 3 Department of Finance, Banking and Economic Analysis, University of Craiova, 200585 Craiova, Romania; \\ roxana.badircea@feaa.ucv.ro \\ 4 Department of Economics, Accounting and International Affairs, University of Craiova, \\ 200585 Craiova, Romania; luminita.vochita@feaa.ucv.ro \\ 5 Department of Management, Marketing and Business Administration, University of Craiova, \\ 200585 Craiova, Romania; maria.enescu@feaa.ucv.ro \\ * Correspondence: george.ionescu@profesor.rau.ro; Tel.: +407-4475-4752
}

Received: 15 October 2019; Accepted: 13 November 2019; Published: 18 November 2019

check for updates

\begin{abstract}
This paper aims to identify the current level of implementation of the principles of sustainable development among hotels in the mountain area of Romania, how these standards influence the occupancy rate with the help of communication strategies, and to what extent the implementation of international management standards leads to an increase in the profitability rate. The research was carried out on the basis of questionnaires addressed to the hotels in the mountain areas of Romania, with information being collected from a number of 77 hotels, rated between 2 and 5 stars. The results obtained from the research highlighted the existence of positive correlations, both between the use of a communication strategy on the sustainable development objectives and the occupancy rate, as well as between the implementation of international management standards and the increase of the profitability rate.
\end{abstract}

Keywords: sustainable development; mountain hotels; mountain tourism; sustainable development goals (SDGs); Romania; international management standards

\section{Introduction}

The tourism sector is considered to be an extremely important area for the world economy and, above all, for Europe. Tourism is an essential factor of growth and prosperity for mountain areas, generating positive, direct and indirect effects for the local and regional economy. However, at the same time, it is necessary to protect the natural environment, and in order to generate a maximum and long-term profit for the community it is necessary that the negative effects be addressed and kept under control. The problem becomes even more sensitive especially in fragile territories, such as protected areas and national parks, where a sustainable approach is essential. Nevertheless, the issue of sustainable development is important for all mountain areas, these having the common feature of the existence of a rich ecological and cultural heritage, which must be valorized but also preserved for the next generations. 
With an accentuated dynamic and a high share of the contribution to global GDP, tourism is currently generating unlimited development opportunities but also the freedom to travel, thus being an open system with extraordinary benefits on society, the economy and the environment $[1,2]$.

The fact that international tourism is growing including emerging economies, is actually a consequence of new business models, cost of travel that is accessible, and facilities for obtaining visas. Thus, international tourist arrivals increased by $5 \%$ in 2018, reaching 1.4 billion people. At the same time, export revenue generated by tourism increased by up to $\$ 1.7$ trillion. For the seventh consecutive year and in 2018, tourism exports increased faster than merchandise exports, thus reducing the trade deficit in many countries. With such an increase, there is a much greater responsibility in ensuring the efficient management of destinations. Thus, the management of tourism in a sustainable way for the benefit of all is absolutely mandatory [3].

At the same time, the opening of tourism on a global level can cause, in time, mass destruction of the environment, an aspect that imposes restrictions in terms of the way in which the trips are carried out, the type of tourism practiced, the destinations targeted and the selected reception structures $[4,5]$. Also the digitization and innovation increased accessibility and changes of the company influence the activity of the tourism sector. Therefore, both tourism destinations and tour companies will have to adapt quickly to changes in order to remain competitive, in parallel with the development of tourism as a means of achieving the Sustainable Development Goals (SDGs) [6].

Sustainable tourism starts from the place of development, the typology of general and specific infrastructure, the responsible management of human, financial and environmental resources, the sustainable management of the destinations and, last but not least, the responsible actions of the people. Being responsible or not in relation to tourism activities, it has to do with the local, national, regional and global management system in conjunction with the global policy of sustainable development of the economy and the environment $[7,8]$.

There is an urgent need to mobilize all available resources to achieve the SDGs. Thus, the tourism sector can be a strong promoter of sustainable development, as companies offer jobs, infrastructure, innovations and important social services [9].

In order to establish the right incentives, a better understanding of the influencing factors, as well as the constraints, is needed for companies and investors interested in tackling the sustainable development of their businesses. In this respect, the 2030 Agenda for Sustainable Development has agreed that the goals and targets of sustainable development must be met for all nations and peoples and for all segments of society [10].

Thus, the structured, standardized approach to economic activities is currently achieved through ISO management system standards, which directly contribute to the achievement of the UN Sustainable Development Goals. At the same time, the economic, environmental and social dimensions are addressed directly by ISO standards, which are also effective tools for ensuring progress. As mentioned above, the 2030 Agenda is a rigorous, sustained action plan that requires the input of all elements of society, including local and national governments, businesses, industry and individuals. To be successful, the process requires consensus, collaboration and innovation.

International standards promoted by ISO and related documents cover almost every industry, from technology to food safety, to agriculture and healthcare, including tourism, providing a solid basis for innovation and progress and are essential tools to help governments, industry and consumers contribute to achieving each of the SDGs [11]. For the hotelier industry, of all the existing standards three in particular, ISO 9001 (Quality management), ISO 14001 (Environmental management) and ISO 45001 (Health and safety management), definitely have the greatest impact on achieving SDGs.

We note the sustained and constant efforts in the direction of global awareness of the specific problems of tourism, on specific forms of tourism. In this new context, in recent years, the problems of mountain areas (distinct part of global tourism), have come to the forefront of the political agenda of many national and international agencies and governments [12]. In this respect, in order to increase the 
awareness of sustainable tourism development worldwide, the year 2002 was declared the International Year of the Mountains and also the International Year of Ecotourism.

Within the forms of tourism, the mountain area through the unique features of the arrangements, it is one of the most popular destinations for tourists, the development of mountain tourism being a key factor in increasing the quality of life of people through initiatives of sustainable economic development and conservation of the environment. On the other hand, from a socio-economic and environmental point of view, tourism in the mountain regions represents a source of problems, but also of opportunities. Mountain regions are, in most cases, inaccessible, fragile, but also homes for some of the poorest people in the world [13].

Mountain tourism is part of Romania's tourist heritage, which is currently perceived differently by tourists, due to its individual attractiveness elements generated by natural, cultural, heritage and social factors. Romania is a destination for mountain tourism with a good attractiveness on the domestic tourism market, possessing a natural potential that favors the practice of specific forms of tourism, especially for winter sports, ski tourism, these being the main reasons for traveling in the mountain areas.

At the European level, the Carpathian Mountains are the second largest mountain range, and they dominate the center of Romania, with 14 peaks reaching over 2000 meters. Romania is also a quite unknown and undiscovered mountain holiday destination, having 44 ski resorts with approximately 150 ski lifts, of which $20 \%$ have been installed or renewed in the last 15 years, also having a competitive advantage on the European market based on current level of prices, which are relatively low compared to most of Europe. On the other hand, Romania's main problem is poorly developed access roads and that is often a problem. However, the Romanian ski resorts are estimated to attract about 1.2 million ski visits per year.

Important to note is the fact that, in Europe, more and more tourists are choosing mountain destinations for holidays. In this context, the development of tourism can be an opportunity for achieving a sustainable development of the mountain, being the source of income, of protecting and capitalizing on natural resources in a sustainable way. Thus, there is a need for the owners of hotels and restaurants to implement sustainable development programs and measures. In this context, the Alpine Convention has published a guide to good practices for mountain hotels to improve their energy efficiency and minimize waste [14,15].

In Romania, as in other European mountain tourist destinations, a series of projects has been developed and implemented in the last decade which has proved to be largely useful and which has positively influenced the attractiveness and performance of mountain resorts. It is also important to emphasize that the mountain tourism faces specific problems that must be integrated and solved: inaccessibility, vulnerability, high altitudes, isolated, customs and specific lifestyles, pressure of tourists in well-equipped areas for winter sports and developed from the point of view of the number of reception structures, seasonality, slow response to the implementation of sustainable technological facilities. It is obvious that current global trends require changes to mountain tourism business models, starting with the management and marketing of mountain tourism destinations, and continuing with the development of general and specific infrastructure, which is a real challenge for Romanian mountain tourism [16-19].

Starting from the fragility of the mountain areas, from the perspective of the climatic and environmental changes, from the massive pressure of the tourists from the Romanian mountain areas over-exploited (Prahova Valley), we set out in this study to identify the extent to which at the level of the Romanian hotels there are concerns about sustainable development, the degree of implementation of sustainable development standards, within which types of hotels we identify the most innovative and performing environmental standards, which is the typology of the hotels that have implemented ISO standards, what types of certifications these hotels have, and their performance as a consequence of ISO implementation. 
The choice of hotels in the mountain areas in our research is also justified by the fact that the mountain, by its nature, directly contributes to achieving the specific objectives of global sustainable development. We support this aspect by the fact that the protection of mountain areas makes a decisive contribution to the management of water resources, by the fact that the mountain is the basic element in the global water supply but also in the supply of green energy, wind energy, and solar energy.

The paper is divided into five sections, starting with an introduction, followed by literature review. Section 3 includes information on the Material and Methods used to carry out the research. Further, in Section 4 the main results are discussed and Section 5 offers the main conclusion of the research.

\section{Literature Review}

Globally, sustainable tourism is becoming increasingly widespread-not only is customer demand for this type of tourism growing, but also suppliers in the tourism area keep developing new green programs and governments increasingly create policies aimed at encouraging sustainable tourism practices. Achieving sustainable tourism is an ongoing process that requires constant monitoring of impacts and introducing the necessary preventive and/or corrective measures. Furthermore, sustainable tourism should maintain a high level of satisfaction for tourists, making them more aware of sustainability issues and promoting sustainable tourism practices among them.

The sustainability of tourism is one of the most debated topics, the attention given being materialized in the elaboration of complex monitoring systems, there being a wide range of general and specific indicators. It should also be noted that each type of destination is unique, and the use of indicators is made specifically, taking into account the character and particularities of the environment but also the type of management of the destination [20].

In this sense, a relevant starting point in defining the set of sustainable principles is the one proposed by the "World Wildlife Fund and Tourism", which proposes the following central elements of the specific policies: the use of sustainable resources, the reduction of excessive consumption and waste, the maintenance diversity, integrating tourism into specific regional development programs, supporting local economies by involving local communities, permanent collaboration of the private and public sector, and implementation of responsible marketing in tourism [4].

Moreover, the European Union (EU) sustainable development strategy and the Lisbon Treaty recognize tourism as an important factor in improving the quality of life and business competitiveness through the sustainable development of all forms of tourism (mountain, coastal, cultural, eco, spa, etc.) and implementation of activities compatible with environmental protection laws. These strategic directives highlight the important role of tourism in the development of regions, but also the need for an integrated quality approach through consumer satisfaction based on economic, social considerations and the ecological dimensions of sustainable development. Many researchers have emphasized the need and importance of the policies promoted and implemented at the level of tourist destinations, specific structures, exploitation of tourist resources, individual and collective human actions [5,21-27].

Sustainable consumer behavior, far from being sufficiently outlined and well-grounded, was defined by the Organization for Economic Cooperation and Development (OECD) as social, economic and political through activities aimed at the consumption of goods and services that contribute to better product quality [28]. At the same time, it is emphasized the reduction of the quantity of waste, the sustainable use of the natural resources, of the toxic materials and of the emissions to respond effectively to the needs of future generations [7,29].

In this context we point out two fundamental elements, on the one hand the limits of the environment (as exhaustible resources) and, on the other, the human needs (the needs of businesses and society), with direct reference to meeting the needs of visitors and locals.

Although interest in the development of mountain tourism has increased in many countries, there are not yet many well-conceptualized models of sustainable best practices. But there are multiple perspectives for improving the situation, as more researchers become interested in the problems specific to mountain tourism $[11,30]$. Thus, the aim is to define a conceptual framework aimed at the planning 
and management of recreational mountain areas based on their essential characteristics: diversity, marginality, difficult access, fragility, niche and aesthetics [31].

Protecting, maintaining or enhancing the sustainable development of mountain destinations is a key challenge in the tourism sector. There are many players involved, which makes destination management much more complex. Therefore, there are a number of theories, models that have been developed to meet this challenge but also to provide a perspective on the complexity of mountain destination management [32].

Basically, the existing models of destination competitiveness and the innovative elements applied to mountain destinations, constitute the reference base from which the innovation elements derive. These are classified by importance, and the innovation factors are subsequently determined. Identifying the importance of innovation elements and grouping them into factors provides knowledge for researchers, destination managers and other stakeholders in the sustainable development of mountain destinations. Therefore, what appears to be an absolute necessity is identifying the interactions between the tourist environment, innovation and the sustainable development of the destination, and in this context, the tourist environment targets the political, economic, technological and ecological natural, cultural, social environments, which are extremely important for determining the competitiveness of the destination [33,34].

The 2030 Agenda defines the 17 SDGs that are designed to be the main instrument for planning and implementing UN sustainable development activities at the level of each country and each type of activity. The latest reform of the United Nations development system (UNDS) involves a set of far-reaching changes in the way the UN development system works to help countries around the world in achieving the targets set [35]. In this context, tourism, as a promoter of sustainable development, needs to be structured to respond to global challenges, including those related to poverty, inequality, climate, environmental degradation, prosperity, peace and justice.

In this context, we must also mention the fact that, at the international level, in the hospitality industry, a multitude of strategies aimed at overcoming the challenges generated by the implementation of ISOs are promoted. Moreover, recent research shows that the hotels' progress in terms of economic performance, increasing their market share and visibility are related to the implementation of ISOs, especially ISO 9001 [36-39].

Recognizing the impact of tourism on the environment, new international strategic guidelines have been created as quality standards especially for accommodation facilities to help them reduce their negative impact on the environment. On the other hand, we emphasize that accommodation facilities can directly contribute to many of the 17 SDGs, because accommodation facilities have immense potential for improving their environmental impact, promoting social exchange and contributing to local economies in a positive way. However, although we have identified many sustainable tourism programs worldwide, there has never been an international standard specifically allocated to accommodation structures [40-42].

Today, international standards related to tourism have evolved, with real tools that help organizations better position themselves on the market (ISO 20488, online consumer reviews), increasing their competitiveness (ISO 22525, medical tourism) and contributing to the Agenda. 2030 for Sustainable Development. Standards such as ISO 21416 (sustainable practices for the environment), ISO 21401 (sustainability management systems for accommodation units) and ISO 20611 (sustainable practices for adventure tourism) are essential for meeting the SDGs-notably SDG 14 (Life Under Water), SDG 12 (Responsible Production and Consumption) and SDG 15 (Life on Land) [43].

Although these standards are based on the same type of management and management principles, in tourism we are talking about two main meta-standards that have been adopted by more than 1.3 million organizations worldwide: ISO 14001 and ISO 9001. They include a range of very broad aspects such as quality management (e.g., ISO 9001), environmental management (e.g., ISO 14001), prevention of occupational hazards and promotion of occupational health and safety regulations (e.g., OHSAS 18000) and corporate social responsibility (e.g., SA 8000) [44]. 
However, managerial performance is an important determinant of the successful implementation of sustainable development initiatives, and we also highlight the fact that the failure to implement ISO standards also generates negative effects on business performance. As a result, a clear understanding of ISO standards and implementation methodology determines the success/failure of any business in the tourism industry and beyond $[37,45]$.

On the other hand, there are many environmental standards used in hotels, including those for developing green skills (green training), motivating green employees (managing green performance and evaluation systems-green salaries and rewards) but also facilitating green opportunities (green involvement of employees) all through a sustainable organizational culture that directly contributes to the sustainable development, eco-culture of hotels [46,47].

Last but not least, the way in which companies manage to implement social responsibility standards is not to be neglected. This is because corporate social responsibility defines the ability of a company to be socially responsible for the growth and development of the environment in which it operates. The effect is indisputably a visible one, by improving the brand image that the company has in the company. Moreover, the ability of a company to engage in environmental protection, through charitable programs and community relations generates performance and competitive advantages over its competitors [48-50].

The main purpose of this paper is to investigate the most important aspects regarding the implementation of sustainable development standards in the hospitality industry in the mountain areas of Romania. As mentioned above, the sustainable development of Romanian mountain tourism is a strategic priority, with major and long-term implications. Romania is a growing mountain destination, with a huge mountain potential, insufficiently exploited and which can be integrated into the European circuit by promoting and developing an eminently responsible mountain tourism. In Romania there are a total of 8453 tourist reception structures, of which 1616 are hotels, and in the mountain area there are 2374 tourist reception structures, of which 208 hotels classified between 1 and 5 stars.

We emphasize this aspect, by the nature of the natural resources exploited in the mountain areas, by the necessity to implement and respect the strategies of sustainable development, as an absolutely mandatory condition of the performance and the long-term development of the Romanian mountain resorts. This is because Romania's mountain tourism is facing a paradoxical situation, on the one hand we identify a huge mountain potential (the presence of the Carpathian Mountains on 1/3 of the surface of Romania) and on the other hand a limited use of the mountain areas from the perspective of the tourist reception structures (representing $28.1 \%$ of the total reception structures, and representing only $12.9 \%$ of the total hotels), of the specific equipment for winter sports (e.g., no ski facilities) and other forms of tourism, respectively rural tourism, ecotourism etc. to which is joined the massive territorial concentration of the receiving tourist structures in only two counties (Prahova and Brasov-outlined with blue) out of 41 counties, plus Bucharest (Figure 1).

Romania, as a member of the United Nations (UN), has adhered to the 17 SDGs of the 2030 Agenda and has assumed the implementation of sustainable development strategies. In this context, the implementation of the SDG at the level of all activity fields was also achieved in Romania by defining and implementing standardization, which directly contributes to the functioning of the single market and to the free movement of products and services on the European market.

From the perspective of the Romanian tourism industry, the application of harmonized standards is voluntary and hoteliers can choose any other solution that offers information regarding compliance with legal requirements in accordance with the essential requirements of the directives on achieving the SDGs and the implementation of European regulations. 


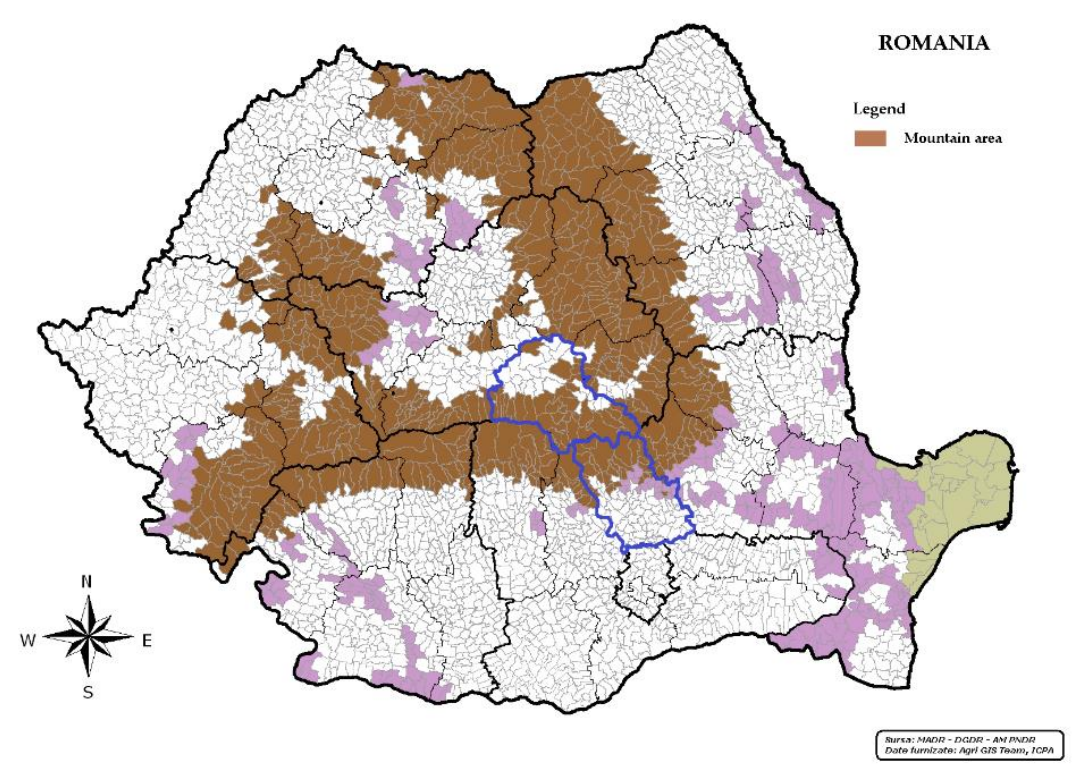

Figure 1. Mountain area covers $29.9 \%$ of Romanian territory. Source: own construction.

Given the voluntary nature of the application of the standards in the reception structures in Romania, they must explicitly provide that their application is the recommended way. Moreover, only in special situations, the application of a Romanian standard may become, in whole or in part, national, local or zonal, through a regulation, when for reasons of public order, protection of life, health and security of persons Such a measure is necessary for physical, environmental and consumer interests (Law No. 163/2015 on national standardization).

Thus, the regulations should include only references to the Romanian standards elaborated and approved at national level, as well as to the Romanian standards that adopt at national level European standards, international standards or standards of other countries.

In this context, the present research comes to fill the knowledge gap regarding the sustainability of hotels in the mountain area of Romania, bearing in mind that there are no studies so far. Also, the research aims to investigate the contribution made by the implementation of international management standards in achieving the SDGs for the selected hotels, as well as their role in increasing the profitability and competitiveness of the hotels in the mountain area. We consider the following hypotheses:

Hypothesis 1. The implementation of sustainable tourism criteria and their communication to customers contributes to increasing occupancy rate of hotels in the mountain area of Romania.

Hypothesis 2. The implementation of international management standards contributes to increasing the profitability of hotels in the mountain area of Romania.

Taking into account the diversity of the results of the previous research, we want this study to contribute to the development of knowledge through the analysis made at the level of the companies in the Romanian hotel industry, as well as provide managers with the knowledge and tools needed to make the best decisions.

\section{Materials and Methods}

According to the latest available statistical data, in 2018 a total number of 2374 tourist reception structures were operated in the Romanian mountain area, of which 208 were classified as hotels, rated between 1 and 5 stars (Table 1 ). 
Table 1. Hotels in the Romanian mountain area (2018).

\begin{tabular}{ccccc}
\hline \multirow{2}{*}{ Classification } & \multicolumn{2}{c}{ Romania } & \multicolumn{2}{c}{ Mountain Area } \\
\cline { 2 - 5 } & No. of Hotels & No. of Beds & No. of Hotels & No. of Beds \\
\hline 5 stars & 34 & 7877 & 4 & 449 \\
4 stars & 359 & 52078 & 47 & 6320 \\
3 stars & 843 & 84889 & 106 & 7919 \\
2 stars & 337 & 46940 & 45 & 3466 \\
1 star & 41 & 3515 & 6 & 398 \\
Total & 1616 & 195457 & 208 & 18552 \\
\hline
\end{tabular}

Source: own construction

In order to carry out this research study, research based on questionnaires distributed to the hotels in the mountain area was carried out between November 2018-April 2019, which sought to obtain data regarding the behavior and actions of the hotel management regarding the principles of sustainable development and how they are transposed into practice. It also was aimed at obtaining information on the state of implementation of ISO Standards and the economic effects seen after implementation of these standards. Taking into account the selected hotel sample and the fact that the hotel managers are involved and have responsibilities both in the implementation of international management standards and in the implementation of sustainable development standards, we decided to ask them to answer the questionnaire used.

Empirical data were collected from valid responses provided by 77 hotels, rated between 2 and 5 stars, through a structured questionnaire with closed questions. Of the responding hotels, $94.8 \%$ had implemented the ISO 9001 standard, 89.6\% had implemented the ISO 14001 standard and $68.8 \%$ had implemented the Occupational Health and Safety Assessment Series-OHSAS 18001. It is worth noting that at present, none of the respondents mentioned the implementation of ISO 9004 or ISO 45001. However, it is necessary to note that in the case of ISO 45001 implementation, companies must migrate to the new standard by March 2021.

Of the 77 hotels that responded to the national survey, $10.4 \%$ belong to a hotel chain and $89.6 \%$ are independent hotels, being distributed according to classification as follows: two 2-star hotels (representing 2.6\%), 54 hotels 3 stars (representing 70.1\%), 19 4-star hotels (representing 24.7\%) and two 5-star hotels (representing 2.6\%). Regarding the size of the selected hotels, 33.8\% have less than 25 rooms, 51.9\% have between 25 and 99 rooms, and 14.3\% have more than 100 rooms (Figure 2).

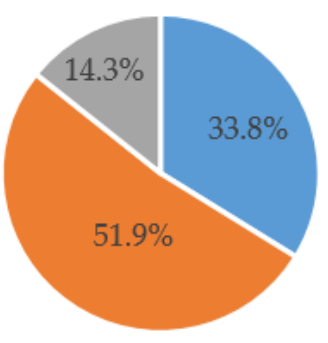

- Less than 25 rooms $\quad 25$ to 99 rooms

n More than 100 rooms

(a) Hotels by size

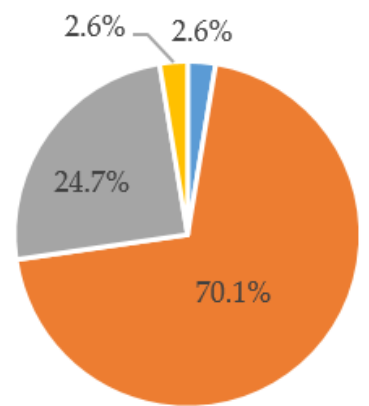

- 2 stars $=3$ stars $=4$ stars $=5$ stars

(b) Hotels by classification

Figure 2. Data breakdown for the mountain area hotels included in the study.

In order to carry out the proposed analysis, the revenue per available room (RevPAR) indicator was chosen as the dependent variable, and the effects perceived after the implementation of ISO 9001, ISO 14001 and OHSAS 18001 were used as independent variables. 
RevPAR is a widely used performance measurement in the hospitality industry, blending together two fundamental hotel outputs, the occupancy rate and the average daily rate (ADR). It measures the efficiency with which the hotel manager uses the available resources-the higher the ratio, the more efficiently the hotel is managed.

All the variables used in this analysis were evaluated following the answers received from the respondents to the closed questions addressed in the questionnaires. For each variable taken into account, the conversion of value judgments into numerical expressions was performed using a five-point Likert scale, as follows: 5 meaning "has increased a lot"; 4 meaning "has increased a little"; 3 meaning "has not changed"; 2 meaning "has dropped a little"; 1 meaning "has decreased a lot".

To determine the minimum number of completed questionnaires ( $N$-sample size) required for this research, two methods have been considered. The first method, presented by Tabachnick and Fidell [51] and Izenman [52], refers to determine $N=50+8 *$ independent_variables. The second method recommends a minimum ratio of 15 to 1 between the number of respondents and the number of independent variables $[53,54]$. Thus, for current research, the number of independent variables is three, so a sample of $N=77$ respondents was set, providing a 25.67 respondents to independent variables ratio.

The available data have been processed and analyzed using the IBM SPSS Statistics [55] software program and Microsoft Excel [56].

\section{Results and Discussions}

The first objective of the research was to obtain an overview of the level of adoption and implementation of specific policies and strategies to support sustainable development within hotels in the mountainous area of Romania. For this, the first part of the questionnaire contained a series of closed questions, with the answer yes or no, regarding the identification of the sustainable development standards that are implemented at the level of each hotel and if there is a communication policy to the clients regarding the existence and the application of these standards.

Thus, seven of the most common performance indicators were selected regarding the fulfillment of the criteria recommended by the Global Sustainable Tourism Council [57], respectively: energy conservation (from boilers to lighting systems, kitchen equipment, automated energy management systems), water conservation (within guest rooms, kitchens, laundries, or pools and spas, linen and towel reuse programs), waste reduction (unnecessary packaging is avoided, existence of food waste composting programs), recycling programs (for newspapers and beverage containers, or reducing the use of paper), food preparation (integrating local production, using fresh and seasonal products, sustainable and healthier cuisine), use of biodegradable cleaning products (reducing the use of products with chlorine bleach and petrochemical derivatives, promoting more natural products), and reducing the use of plastics (offering different alternatives such as water dispensers and refillable bottles, the use of wood or paper as a replacement, eliminating plastic straws). The results are presented in Table 2.

Table 2. Sustainability performance indicators for Romanian hotels in the mountain area.

\begin{tabular}{ccc}
\hline Indicator & No. of Hotels & Percentage \\
\hline Energy conservation & 74 & $96.1 \%$ \\
Water conservation & 68 & $88.3 \%$ \\
Waste reduction & 62 & $80.5 \%$ \\
Recycling programs & 65 & $84.4 \%$ \\
Food preparation & 63 & $81.8 \%$ \\
Biodegradable cleaning products & 53 & $68.8 \%$ \\
Reducing the use of plastics & 11 & $14.3 \%$ \\
\hline
\end{tabular}

Source: own research. 
At a first analysis it can be observed that, in general, the hotels in the mountain area of Romania report in a significantly large proportion the implementation of measures and indicators that dream of sustaining and implementing the standards of sustainable development, making sustained efforts in this regard. However, there are also two exceptions where relatively lower weights are registered, namely the use of biodegradable cleaning products ( $68.8 \%$ of the respondents) and reducing the use of plastics (with a very low $14.3 \%$ ). A possible explanation for these relatively low weights compared to other indicators may be that the purchase price is slightly higher than in the case of alternatives, as well as the insufficient degree of market maturity and the demands of the customers of these hotels. Probably, over time, with the increase of the sophistication of the tourist services market and of the requests received from the clients, these percentages will increase considerably.

Regarding the existence of a communication policy to the clients regarding the sustainable development objectives, as well as of the measures adopted by the hotels in order to support these objectives, it is noted the receipt of a positive response from 55 hotels, representing $71.4 \%$ of total sample selected. Depending on the comfort category to which the hotels are classified, the situation regarding the communication policy regarding sustainable development is presented in Table 3.

Table 3. Sustainability communication for Romanian hotels in the mountain area.

\begin{tabular}{ccc}
\hline Classification & No. of Hotels & Percentage \\
\hline 5 stars & 2 & $100 \%$ \\
4 stars & 19 & $100 \%$ \\
3 stars & 34 & $63 \%$ \\
2 stars & 0 & $0 \%$ \\
Total & 55 & $71.4 \%$ \\
\hline \multicolumn{3}{c}{ Source: own research. }
\end{tabular}

Analyzing the obtained results, an important conclusion is that the existence of the communication policy to the clients regarding the sustainable development objectives is present in all the hotels classified in category 4 and 5 stars, but it is not a sufficiently consistent presence in the case of the hotels classified with 3 stars. In the case of 2-star hotels, they did not report the existence of a well-defined communication strategy. However, on the whole, the existence of a coherent communication strategy regarding the sustainable development objectives of $71.4 \%$ can be considered relevant and encouraging for the future.

In order to verify the efficiency of the implementation and use of a strategy for communicating sustainable development objectives, the existence of simple correlation relationships with the change of the hotel occupancy rate after the implementation of the respective strategy was verified. The quantification of the perceived change in the degree of occupation was performed with the help of a five-point Likert, according to the methodology described above, and the results are presented in Table 4.

Table 4. Partial correlation matrix for sustainable development communication and occupancy rate.

\begin{tabular}{cccc}
\hline & & Communication Strategy & Occupancy Rate \\
\hline Communication & Pearson Correlation & 1 & $0.314^{* *}$ \\
Strategy & Sig. (2-tailed) & & 0.005 \\
& $\mathrm{~N}$ & 77 & 77 \\
\hline Occupancy & Pearson Correlation & $0.314^{* *}$ & 1 \\
Rate & Sig. (2-tailed) & 0.005 & 77 \\
\hline
\end{tabular}

** Correlation is significant at the 0.01 level (2-tailed). Source: own construction using SPSS. 
As can be seen, it is possible to identify the existence of a positive correlation of medium intensity between the implementation and maintenance of a strategy of communicating the sustainable development objectives to the clients and the occupancy rate of the hotel, the clients being receptive and reacting positively. Obviously, there are multiple advantages of implementing a communication strategy on sustainable development objectives, for both hotels and customers, and these advantages will become increasingly important in the years to come.

It is obvious that bidirectional communication between hotels and customers brings benefits to both parties. It is possible that the extension of the research sample also in the area of hotels outside the mountain area will bring improvements in terms of research results. As Tölkes [58] argues, sustainability communication in tourism is an emerging research topic and little is understood about personal communication channels and message factors that lead to positive consumer reactions.

The findings of our research suport and complement the results obtained from recent studies. Wehrli et al. [59] states that sustainable tourism products are distinct from standard alternatives and the hotels need to market these differently, creating a stronger connection with the tourist destination, raising awareness, focusing on innovation and originality. At the same time, Font and McCabe [60] show that there are many innovative solutions to sustainability challenges and that there is a growing impetus for the development of more sustainable tourism products and a wide range of approaches can be used to understand how consumers are influenced to make more sustainable choices that do not compromise their primary motivations.

However, it should be noted that the communication strategy can play a decisive role in achieving the managerial goals regarding the degree of employment, as well as in the achievement of the SDGs' specific indicators. As Mercade Mele et al. [61] note, in addition to the implementation of green measures and their communication through green marketing, hotel companies should continue to develop direct green actions (such as reducing raw materials and minimizing energy use, or providing certifications for products and services) in order to positively impact the company's performance.

In this case, for Romanian mountain hotels, based on the results obtained we can conclude that Hypothesis 1 is verified, considering that the implementation of sustainable tourism criteria and their communication to customers contributes to increasing occupancy rate of hotels in the mountain area of Romania.

A second objective of the present research was to investigate whether the implementation of ISO standards influences the profitability of the selected hotels. In order to achieve this objective, in the second part of the questionnaire administered among the hotels in the mountainous area of Romania, a series of closed questions were asked, with a yes or no answer, regarding the implementation of international management standards, along with questions closed by type five-point Likert scales for estimating the effects perceived after the implementation of these standards and for estimating the perceived changes on the RevPAR indicator (Table 5).

Table 5. Implementation of ISO standards in Romanian hotels in the mountain area.

\begin{tabular}{ccc}
\hline International Standard & No. of Hotels & Percentage \\
\hline ISO 9001 & 73 & $94.8 \%$ \\
ISO 9004 & 0 & $0 \%$ \\
ISO 14001 & 69 & $89.6 \%$ \\
OHSAS 18001 & 53 & $68.8 \%$ \\
ISO 45001 & 0 & $0 \%$ \\
\hline
\end{tabular}

Source: own construction using SPSS.

At a first examination of the results of the implementation of international management standards, one can notice the relatively high percentage of their adoption among hotels in the mountainous area of Romania. Thus, the largest implementation is found in the case of ISO $9001(94.8 \%)$, followed by ISO $14001(89.6 \%)$ and OHSAS 18001 (68.8\%). On the other hand, the lack of implementation of the 
standards ISO 9004 and ISO 45001 can be noted. The transition from OHSAS 18001 to ISO 45001 is expected to take place within a period of 3 years from the date of adoption in year 2018.

Following the analysis, we verified the existence of correlation relations between the effects perceived after the implementation of ISO standards and the evolution of the RevPAR indicator (Table 6).

Table 6. Partial correlation matrix for effects of revenue per available room (RevPAR) and international management standards.

\begin{tabular}{|c|c|c|c|c|c|}
\hline & & RevPAR & ISO 9001 & ISO 14001 & OHSAS 18001 \\
\hline \multirow{3}{*}{ RevPAR } & Pearson Correlation & 1 & $0.807^{* *}$ & $0.603^{* *}$ & $0.337^{* *}$ \\
\hline & Sig. (2-tailed) & & 0.000 & 0.000 & 0.003 \\
\hline & $\mathrm{N}$ & 77 & 77 & 77 & 77 \\
\hline \multirow{3}{*}{ ISO 9001} & Pearson Correlation & $0.807^{* *}$ & 1 & $0.529 * *$ & $0.264 *$ \\
\hline & Sig. (2-tailed) & 0.000 & & 0.000 & 0.020 \\
\hline & $\mathrm{N}$ & 77 & 77 & 77 & 77 \\
\hline \multirow{3}{*}{ ISO 14001} & Pearson Correlation & $0.603^{* *}$ & $0.529 * *$ & 1 & $0.517^{* *}$ \\
\hline & Sig. (2-tailed) & 0.000 & 0.000 & & 0.000 \\
\hline & $\mathrm{N}$ & 77 & 77 & 77 & 77 \\
\hline \multirow{3}{*}{ OHSAS 18001} & Pearson Correlation & 0.337 * & $0.264^{*}$ & $0.517^{* *}$ & 1 \\
\hline & Sig. (2-tailed) & 0.003 & 0.020 & 0.000 & \\
\hline & $\mathrm{N}$ & 77 & 77 & 77 & 77 \\
\hline
\end{tabular}

${ }^{* *}$ Correlation is significant at the 0.01 level (2-tailed). ${ }^{*}$ Correlation is significant at the 0.05 level (2-tailed).Source: own construction using SPSS.

Analyzing the obtained results, it can be observed that the most significant relationship exists between RevPAR and the effects of the implementation of ISO 9001 and ISO 14001, establishing a direct medium strong link between them. Also, there can be a relationship between RevPAR and OHSAS 18001, but the connection is not as strong as in the other two factors considered.

To explore the relationships between the effects of implementing international management standards and RevPAR, we used the selected variables to develop a model.

The model summary (Table 7) and the results of applying the analysis of variance (ANOVA) methodology (Table 8) shows that Model_1, as a whole, is statistically significant, meaning that regressors' influence is significantly greater than that of residues. the calculated value of F-statistic $=55.763$ is significantly greater than the critic value $\mathrm{F}_{0.05 ; 3 ; 73}=2.74$, and on the value of and Sig. $=0.000<\alpha=0.05$.

Table 7. Model summary for Model_1.

\begin{tabular}{ccccc}
\hline \multicolumn{4}{c}{ Model Summary } \\
\hline $\boldsymbol{R}$ & R_Square & Adjusted R_Square & Std. Error of the Estimate & Durbin-Watson \\
\hline $0.834^{\mathrm{a}}$ & 0.696 & 0.694 & 0.598 & 1.558 \\
\hline $\begin{array}{l}{ }^{\mathrm{a}} \text { Dependent Variable: RevPAR. } \\
\text { construction by }{ }^{\mathrm{b}} \text { Pring SPSS. }\end{array}$ & & &
\end{tabular}

Table 8. Analysis of variance (ANOVA) for Model_1.

\begin{tabular}{cccccc}
\hline \multicolumn{7}{c}{ ANOVA } \\
\hline & Sum of Squares & df & Mean Square & F & Sig. \\
\hline Regression & 59.837 & 3 & 19.946 & 55.763 & $0.000^{\text {a }}$ \\
Residual & 26.111 & 73 & 0.358 & & \\
Total & 85.948 & 76 & & & \\
\hline
\end{tabular}

a Predictors: (Constant), ISO 9001, ISO 14001, OHSAS 18001. Source: own construction by using SPSS. 
After a brief analysis of the data in Table 7, a medium influence of predictors' values on RevPAR is shown. A first information in this respect is offered by the value of the multiple correlation coefficient $(R=0.834)$, showing that there is a high intensity correlation between the result variable RevPAR and the predictors. The value of the determination coefficient $R \_$Square $\left(R^{2}\right)$ shows that the variation of RevPAR is determined in proportion of $69.6 \%$ by the combined variability of predictors, which is very relevant for this research. The smaller than $0.05 \mathrm{Sig}$. value indicates that the model is generalizable from the sample to the population. Therefore, the null hypothesis is rejected and the alternative one is accepted, meaning that Model_1 is valid (statistically significant) for the chosen significance level.

The situation of the regression coefficients, the standard errors, the $t$ statistical test value, the Sig. value and the collinearity statistics are presented in Table 9.

Table 9. Characteristics of Model_1 coefficients.

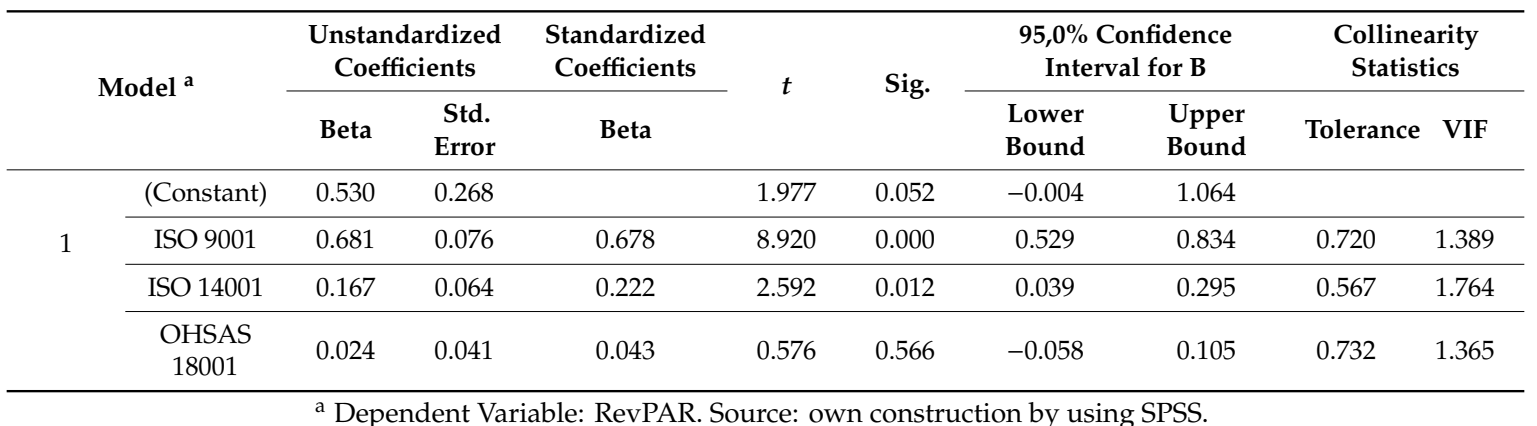

As foreshadowed, from the interpretation of the characteristics of Model_1 coefficients, it is observed that in the case of the variable OHSAS 18001, the value Sig. $0.566>0.05$, which suggests its elimination from the model, due to the lack of statistical significance. The VIF values are between 1 and 10 , so it can be concluded that there are no multicollinearity symptoms.

The multiple linear regression model reflecting the correlation between the RevPAR values and those of the three considered standards is as follows:

$$
\text { Model_1 }: \text { RevPAR }=0.530+0.681 \times \text { ISO9001 }+0.167 \times \text { ISO14001 }
$$

In order to verify the existence of some influential cases that may affect the values of the regression coefficients [62], Cook's distance values were checked. Since all 77 values of Cook's distance were much smaller than 1 , it was clear that there were no influential cases within the sample and, therefore, the values of the $b_{k}$ coefficients were not influenced by these (Table 10):

Table 10. Residuals statistics.

\begin{tabular}{cccccc}
\hline & Minimum & Maximum & Mean & Std. Deviation & N \\
\hline Residual & -1.437 & 1.745 & 0.000 & 0.586 & 77 \\
Std. Residual & -2.402 & 2.917 & 0.000 & 0.980 & 77 \\
Stud. Residual & -2.495 & 3.162 & 0.000 & 1.020 & 77 \\
Cook's & 0.000 & 0.438 & 0.022 & 0.057 & 77 \\
Distance & \multicolumn{7}{c}{ Source: own construction by using SPSS. }
\end{tabular}

As a final conclusion, the Model_1 qualified for being used in the analysis of the predictors' (ISO 9001 and ISO 14001) influence on RevPAR, and we can demonstrate the existence of a countable influence of the implementation of international management standards on the profitability of hotels in the mountain area of Romania.

As Pereira-Moliner and Tari [63] conclude, the certified hotels achieve better performance levels and that quality certification has positive effects on some performance variables, helping hotels to 
better satisfy their customers' needs (then, the hotel's revenues can be increased) and to improve and optimize some cost categories (then, cost can be reduced). On the other hand, in a previous study, Claver et al. [64] found that the most important reasons to adopt and certify quality systems are internal and, on the other hand, that although positive effects on performance can be identified, the impact on financial performance is low.

In other research, Brătucu et al. [65] demonstrated that most hotel managers are concerned with issues linked to sustainable development of the accommodation unit they manage, but, at the same time, the researchers noticed a low interest in sustainable evolution negatively correlated with the comfort level of the accommodation unit. Also, there are a number of researchers who identified the existence of a link between the implementation of quality standards and the increase of hotel performance, but could not prove the existing causal relationships [66,67].

Considering the above, we can conclude that hypothesis 2 is only partially confirmed, because following the study for the Romanian hotels in the mountain area we were able to identify the existence of a direct influence of the implementation of the ISO 9001 and ISO 14001 standards on the RevPAR indicator. However, at the same time, the study highlighted the lack of a direct influence of OHSAS 18001 on the RevPAR indicator, which only partially validates the assumed hypothesis. There is not much similar research on the influence of OHSAS 18001, and for the existing studies it is not possible to identify a clear influence, given that the results are contradictory, varying between positive effects [68] and lack of correlation between the implementation of the international standard and obtaining the expected effects [69].

\section{Conclusions}

The growing importance of tourism for the local global economy has brought great benefits to the mountain regions. Many mountain regions have become accessible through new and modern means of communication due to the increased demand for tourist services. Also, tourism has been the catalyst for the implementation of new ideas, new modes of production and cultural exchange in mountain regions that were until recently closed and conservative. Today, people from many mountain regions around the world owe their wealth to tourism, generating additional income and jobs, new career opportunities and opening up markets for both traditional local products. But the positive economic impact is only a positive side of this global phenomenon. Thus, the growth of tourism, especially in the mountainous areas, is accompanied by the tendency to destroy the bases of its own development, respectively the environment and corrupting the way of life of the inhabitants of these regions.

Starting from the main global demands regarding the sustainable economic development of each field of activity, the present research comes with a series of arguments and conclusions attesting to the positive impact of the implementation of the policies and strategies of sustainable development. Thus, this research we aimed to carry out an analysis of the situation existing in the Romanian hotels located in the mountain area, in order to obtain a current image on their sustainable development, of the indicators used, as well as how the implementation of international management standards can contribute to increasing the profitability of the analyzed hotels.

The results obtained from the research we could say are positive and encouraging for the sustainable development and achievement of the SDGs. Regarding the level of adoption and implementation of specific policies and strategies to support sustainable development within hotels in the mountainous area of Romania, seven of the most common performance indicators were selected regarding the fulfillment of the criteria recommended by the Global Sustainable Tourism Council. The results of the research underlined the existence of a fairly high degree of implementation of these initiatives, in the case of 5 of the 7 indicators analyzed, with weights in the group of hotels analyzed varying between $81.8 \%$ and $96.1 \%$. In the case of two of the analyzed indicators (the use of biodegradable cleaning products and reducing the use of plastics), much lower implementation weights were observed, being mentioned by only $68.8 \%$ and $14.3 \%$ of the respondents respectively. 
The next step was to investigate the existence of a relationship between the existence of a hotel communication strategy to customers regarding the existence and implementation of support indicators for the sustainable development and modification of the hotel occupancy rate after implementing this strategy. In this case the results were encouraging, a number of 55 of the 77 hotels analyzed mentioning the existence of the planned communication. However, it is important to mention that the answers obtained revealed that the existence of the communication strategy is omnipresent in the case of 4 and 5 star hotels, but for the other comfort categories ( 3 and 2 stars) there is still much room for improvement. It was also possible to identify the existence of a positive correlation of medium intensity between the implementation of a strategy of communicating the sustainable development objectives to the clients and the occupancy rate of the hotels.

Regarding the second hypothesis tested through this research, namely that the implementation of international management standards contributes to increasing the profitability of hotels in the mountain area of Romania, the results obtained only partially validate the working hypothesis. Thus, in the case of analyzing the influence of the implementation of the ISO 9001 and ISO 14001 standards, the results obtained fully validate the support that the implementation of these international standards has for the sustainable development of the hotels in mountain areas of Romania and, respectively, the achievement of the objectives assumed through the 2030 Agenda for Sustainable Development. In the case of the third investigated standard (OHSAS 18001), the analysis of the results obtained could neither confirm nor disprove its direct contribution to the sustainable development of hotels. On the one hand, there is a certain degree of correlation between the implementation of this standard and the evolution of the profitability indicators but, on the other hand, the econometric tests could not confirm the direct relationship with the RevPAR indicator.

Although in Romania, as in other countries, there are numerous sustainable tourism programs launched by tourism organizations or other types of organizations, there has never been a truly impartial international standard dedicated to accommodation. This is also the reason why, in some cases, as is the case with many hotels in Romania, implementing sustainable development standards is difficult to achieve and difficult to commensurate. Basically, as our research shows, the standards implemented are minimal, which in the long term influences the sustainability of the hotel industry in the mountainous area of Romania and beyond.

Starting from the results of this research and especially from the new trends already manifested in the global tourism market, Romania must take major steps to open up to the new sustainable management standards and implementing the newest such standards.

In this context we mention the need to implement the new international initiatives and standards promoted at global level, such as ISO 21401, Tourism and Related Services-Sustainability management system for accommodation units. This meets the needs manifested in the global tourism market, offering specific standards for environmental, social and economic problems for the implementation of a management system of sustainability in tourist accommodation. The standard is complex, addressing specific issues such as human rights, the health and safety of employees and guests, environmental protection, water and energy consumption, waste generation and the development of the local economy.

Along with the conclusions stated above, we believe that this research will increase the awareness of the management of hotels in mountain areas, and not only those areas, towards the major importance of approaching a sustainable development strategy by following and reaching the SDGs proposed through the 2030 Agenda for Sustainable Development.

However, the results obtained from this research can be considered as a step forward in identifying the most appropriate implementation of the international management standards and pave the way for new studies targeting the latest proposed standards. A possible research direction opened by this study is the analysis of the degree of penetration and the efficiency of the implementation of the ISO 26000 standard, which is the most complex guide to social responsibility. With over 450 recommendations that directly impact SDGs, ISO 26000 provides clear guidance on how businesses and organizations can work ethically and transparently for sustainable development. 
As far as the limitations of this paper are concerned, we may take into account that the data were obtained through questionnaires, and their completion is based on the subjective perception of the respondents and on their general knowledge of the analyzed issue. Also, it should be noted that this research is based on the Romanian hotel context, thus provoking biased results. Future research may replicate this study in other regions and other countries. However, in the absence of the official data available on the analyzed topic, we consider that the benefits obtained by this research are higher than the existing limitations.

Moreover, it would be interesting to investigate in detail the influence of the communication strategies adopted by the hotels regarding the communication of the sustainable development objectives and the impact reflected on the degree of customer satisfaction and the profitability of the hotels.

Author Contributions: Conceptualization, D.F. and G.H.I.; Investigation, D.F. and G.H.I.; Methodology, R.B., L.V. and M.E.; Validation, R.B., L.V. and M.E.; Writing-review and editing, D.F. and G.H.I.

Funding: This research received no external funding.

Conflicts of Interest: The authors declare no conflict of interest.

\section{References}

1. UNWTO. UNWTO World Tourism Barometer; UNWTO: Madrid, Spain, 2019. Available online: https://www.e-un wto.org/loi/wtobarometereng (accessed on 17 August 2019).

2. McAleer, M. The fundamental equation in tourism finance. J. Risk Financ. Manag. 2015, 8, 369-374. [CrossRef]

3. UNWTO. International Tourism Highlights; UNWTO: Madrid, Spain, 2019. Available online: https://www.eunwto.org/doi/pdf/10.18111/9789284421152 (accessed on 17 August 2019).

4. Jurigová, Z.; Lencsésová, Z. Monitoring system of sustainable development in cultural and mountain tourism destinations. J. Compet. 2015, 7, 35-52. [CrossRef]

5. Crick, A. New third places: Opportunities and challenges. In Tourism Sensemaking: Strategies to Give Meaning to Experience; Advances in Culture, Tourism and Hospitality Research 5; Woodside, A., Ed.; Emerald Group Publishing Limited: Bingley, UK, 2011; pp. 63-77.

6. Yung, R.; Khoo-Lattimore, C. New realities: A systematic literature review on virtual reality and augmented reality in tourism research. Curr. Issues Tour. 2017, 22, 2056-2081. [CrossRef]

7. Dewailly, J.-M. Sustainable tourist space: From reality to virtual reality? Tour. Geogr. 1999, 1, 41-55. [CrossRef]

8. Gretzel, U.; Fesenmaier, D.R.; Formica, S.; O'Leary, J. Searching for the future: Challenges faced by destination marketing organizations. J. Travel Res. 2006, 45, 116-126. [CrossRef]

9. Andereck, K.L.; Valentine, K.M.; Knopf, R.C.; Vogt, C.A. Residents' perceptions of community tourism impacts. Ann. Tour. Res. 2005, 32, 1056-1076. [CrossRef]

10. OECD. Development Co-Operation Report 2016: The Sustainable Development Goals as Business Opportunities; OECD Publishing: Paris, France, 2016.

11. International Organization for Standardization. Contributing to the UN Sustainable Development Goals with ISO Standards; ISO: Geneva, Switzerland, 2018; Available online: https://www.iso.org/files/live/sites/isoorg/files/s tore/en/PUB100429.pdf (accessed on 20 September 2019).

12. Godde, P.M.; Price, M.F.; Zimmermann, F.M. (Eds.) Tourism and Development in Mountain Regions; CABI Publishing: Oxon, UK, 2000.

13. Messerli, B.; Ives, J.D. (Eds.) Mountains of the World: A Global Priority; The Parthenon Publishing Group: New York, NY, USA, 1997.

14. Schröer, J. Management de L'énergie dans les Hôtels Alpins; adelphi: Berlin, Germany, 2017.

15. Funnell, D.; Parish, R. Mountain Environments and Communities; Routledge: London, UK, 2001.

16. Flagestad, A.; Hope, C.A. Strategic success in winter sports destinations: A sustainable value creation perspective. Tour. Manag. 2001, 22, 445-461. [CrossRef]

17. Jianu, E. The improvement of the situation of the contemporary consumer-Education, awareness and protection of his rights and interests. J. Adv. Res. Econ. Int. Bus. 2016, 4, 13-18.

18. Macchiavelli, A. Alpine tourism. J. Alp. Res. 2009, 97, 99-115. [CrossRef]

19. Hjalager, A.-M. Repairing innovation defectiveness in tourism. Tour. Manag. 2002, 23, 465-474. [CrossRef] 
20. UNTWO. Towards Measuring the Economic Value of Wildlife Watching Tourism in Africa; UNWTO: Madrid, Spain, 2015. Available online: https://sustainabledevelopment.un.org/content/documents/1882unwtowildlif epaper.pdf (accessed on 25 August 2019).

21. Bramwell, B.; Lane, B. Sustainable tourism: An evolving global approach. J. Sustain. Tour. 1993, 1, 1-5. [CrossRef]

22. Fyall, A.; Garrod, B. Heritage tourism: At what price? Manag. Leis. 1998, 3, 213-228. [CrossRef]

23. Sharpley, R. Tourism and sustainable development: Exploring the theoretical divide. J. Sustain. Tour. 2000, 8, 1-19. [CrossRef]

24. Pforr, C. Perspektiven einer nachhaltigen Tourismuspolitik-Ein Diskussionsbeitrag. Tour. Rev. 2001, 56, 46-48. [CrossRef]

25. Hardy, A.; Beeton, R.J.S.; Pearson, L. Sustainable tourism: An overview of the concept and its position in relation to conceptualisations of tourism. J. Sustain. Tour. 2002, 10, 475-496. [CrossRef]

26. Farrell, B.; Twining-Ward, L. Seven steps towards sustainability: Tourism in the context of new knowledge. J. Sustain. Tour. 2005, 13, 109-122. [CrossRef]

27. Byrd, E. Stakeholders in sustainable tourism development and their roles: Applying stakeholder theory to sustainable tourism development. Tour. Rev. 2007, 62, 6-13. [CrossRef]

28. OECD. OECD Annual Report 2002; OECD Publishing: Paris, France, 2002.

29. Breukel, A.; Go, F.M. Knowledge-based network participation in destination and event marketing: A hospitality scenario analysis perspective. Tour. Manag. 2009, 30, 184-193. [CrossRef]

30. Beedie, P.; Hudson, S. Emergence of mountain-based adventure tourism. Ann. Tour. Res. 2003, 30, 625-643. [CrossRef]

31. Nepal, S.K.; Chipeniuk, R. Mountain tourism: Toward a conceptual framework. Tour. Geogr. 2005, 7, 313-333. [CrossRef]

32. Crouch, G.I. Modelling Destination Competitiveness: A Survey and Analysis of the Impact of Competitiveness Attributes; CRC for Sustainable Tourism Pty Ltd.: Queensland, Australia, 2007. Available online: https://sustain.pata.org/wp-content/uploads/2014/12/Crouch_modelDestnComp-v2.pdf (accessed on 25 August 2019).

33. Kuščer, K. Determining factors of mountain destination innovativeness. J. Vacat. Mark. 2013, 19, 41-54. [CrossRef]

34. Shavinina, L.V. The fundamentals of innovation education. In The Routledge International Handbook of Innovation Education; Routledge: London, UK, 2013.

35. United Nations. UN development system reform, 2018. United Nations Website. Available online: https://reform.un.org/content/un-development-system-reform-101\#what-is-the-reform-of -the-un-development-system (accessed on 15 September 2019).

36. EL-Hussein, A.; Omar, Q. Modelling the impact of ISO 26000 implementation on Egyptian hotel sector performance. Int. J. Herit. Tour. Hosp. 2018, 12, 214-233.

37. Yusuf, A.; Maryam, A. Corporate social responsibility and company performance. J. Bus. Stud. Q. 2015, 7, 151-166.

38. Djofack, S.; Camacho, M. Implementation of ISO 9001 in the Spanish tourism industry. Int. J. Qual. Reliab. Manag. 2017, 34, 18-37. [CrossRef]

39. Drosos, D.; Skordoulis, M.; Chalikias, M.; Kalantonis, P.; Papagrigoriou, A. The impact of ISO 9001 quality management system implementation in tourism SMEs. In Tourism, Culture and Heritage in a Smart Economy; Katsoni, V., Upadhya, A., Stratigea, A., Eds.; Springer International Publishing: Cham, Switzerland, 2017.

40. Alegre, J.; Sard, M. When demand drops and prices rise. Tourist packages in the Balearic Islands during the economic crisis. Tour. Manag. 2015, 46, 375-385. [CrossRef]

41. Aggeri, F. Environmental policies and innovation: A knowledge-based perspective on cooperative approaches. Res. Policy 1999, 28, 699-717. [CrossRef]

42. Casadesus, M.; Marimon, F.; Alonso, M. The future of standardised quality management in tourism: Evidence from the Spanish tourist sector. Serv. Ind. J. 2010, 30, 2457-2474. [CrossRef]

43. Leal-Millan, A.; Peris-Ortiz, M.; Leal-Rodríguez, A.L. Sustainability in Innovation and Entrepreneurship; Springer International Publishing: Cham, Switzerland, 2018.

44. Heras-Saizarbitoria, I.; Boiral, O. ISO 9001 and ISO 14001: Towards a research agenda on management system standards. Int. J. Manag. Rev. 2013, 15, 47-65. [CrossRef] 
45. Antony, J.; Lizarelli, F.; Fernandes, M.; Dempsey, M.; Brennan, A.; McFarlane, J. A study into the reasons for process improvement project failures: Results from a pilot survey. Int. J. Qual. Reliab. Manag. 2019, 36, 1699-1720. [CrossRef]

46. Pham, N.T.; Tučková, Z.; Chiappetta Jabbour, C.J. Greening the hospitality industry: How do green human resource management practices influence organizational citizenship behavior in hotels? A mixed-methods study. Tour. Manag. 2019, 72, 386-399. [CrossRef]

47. Pham, N.T.; Tučková, Z.; Phan, Q.P.T. Greening human resource management and employee commitment towards the environment: An interaction model. J. Bus. Econ. Manag. 2019, 20, 446-465.

48. Trang, H.N.T.; Yekini, L.S. Investigating the link between CSR and financial performance: Evidence from Vietnamese listed companies. Br. J. Arts Soc. Sci. 2015, 17, 85-101.

49. Gligor-Cimpoieru, D.C.; Munteanu, V.P.; Nițu-Antonie, R.D.; Schneider, A.; Preda, G. Perceptions of future employees toward CSR environmental practices in tourism. Sustainability 2017, 9, 1631. [CrossRef]

50. Peña-Miranda, D.D.; Arteaga-Ortiz, J.; Ramón-Cardona, J. Determinants of CSR application in the hotel industry of the Colombian Caribbean. Sustainability 2019, 11, 5045. [CrossRef]

51. Tabachnick, B.G.; Fidell, L.S. Using Multivariate Statistics, 3rd ed.; Harper Collins: New York, NY, USA, 1996.

52. Izenman, A.J. Modern Multivariate Statistical Techniques, 1st ed.; Springer: New York, NY, USA, 2003.

53. Roscoe, J.T. Fundamental Research Statistics for the Behavioural Sciences, 2nd ed.; Holt Rinehart \& Winston: New York, NY, USA, 1975.

54. Alreck, P.L.; Settle, R.B. The Survey Research Handbook, 3rd ed.; McGraw-Hill: New York, NY, USA, 2003.

55. Popa, M. Statistică Pentru Psihologie. Teorie și aplicații SPSS, 2nd ed.; Polirom: Bucharest, Romania, 2008.

56. Zaharia, M.; Oprea, C. Elemente de Analiza Datelor și Modelare Utilizând Excel; Editura Universitară: Bucharest, Romania, 2011.

57. Global Sustainable Tourism Council. GSTC Industry Criteria, 2016. Available online: https://www.gstcounc il.org/wp-content/uploads/GSTC-Industry-Criteria-for-Hotels-with-indicators-Dec-2016.pdf (accessed on 20 September 2019).

58. Tölkes, C. Sustainability communication in tourism-A literature review. Tour. Manag. Perspect. 2018, 27, 10-21. [CrossRef]

59. Wehrli, R.; Priskin, J.; Demarmels, S.; Schaffner, D.; Schwarz, J.; Truniger, F.; Stettler, J. How to communicate sustainable tourism products to customers: Results from a choice experiment. Curr. Issues Tour. 2017, 20, 1375-1394. [CrossRef]

60. Font, X.; McCabe, S. Sustainability and marketing in tourism: Its contexts, paradoxes, approaches, challenges and potential. J. Sustain. Tour. 2017, 25, 869-883. [CrossRef]

61. Mercade Mele, P.; Molina Gomez, J.; Garay, L. To green or not to green: The influence of green marketing on consumer behaviour in the hotel industry. Sustainability 2019, 11, 4623. [CrossRef]

62. Labar, A.V. SPSS Pentru Ştiinţele Educaţiei: Metodologia Analizei Datelor în Cercetarea Pedagogică; Polirom: Iasi, Romania, 2008.

63. Pereira-Moliner, J.; Tarí, J.J. Quality certification, performance and size in hotel chains. Tour. Econ. 2015, 21, 307-324. [CrossRef]

64. Claver, E.; José Tarí, J.; Pereira, J. Does quality impact on hotel performance? Int. J. Contemp. Hosp. Manag. 2006, 18, 350-358. [CrossRef]

65. Brătucu, G.; Băltescu, C.A.; Neacșu, N.A.; Boșcor, D.; Țierean, O.M.; Madar, A. Approaching the sustainable development practices in mountain tourism in the Romanian Carpathians. Sustainability 2017, 9, 2051. [CrossRef]

66. Vásquez, K.-L.; Balbastre-Benavent, F.; Redondo-Cano, A. Is certification for sustainable tourism complementary to ISO 9000 certification? The case of the Parque del Lago Hotel in Costa Rica. PASOS Revista de Turismo y Patrimonio Cultural 2011, 9, 543-557. [CrossRef]

67. Lleshi, S.; Syka, X. Application of quality management system in tourism sector in Kosovo. Eur. J. Econ. Bus. Stud. 2016, 4, 73-78. [CrossRef] 
68. Bevilacqua, M.; Ciarapica, F.; De Sanctis, I. How to successfully implement OHSAS 18001: The Italian case. J. Loss Prev. Process Ind. 2016, 44, 31-43. [CrossRef]

69. Ghahramani, A.; Summala, H. A study of the effect of OHSAS 18001 on the occupational injury rate in Iran. Int. J. Inj. Control Saf. Promot. 2017, 24, 78-83. [CrossRef] 